\title{
Respiratory symptoms in children at schools near a foundry
}

\author{
Penny Symington, David Coggon, Stephen Holgate
}

\begin{abstract}
A survey was carried out in response to complaints of increased respiratory symptoms in children at schools near a foundry in Walsall, West Midlands. Air monitoring around the factory had shown concentrations of formaldehyde most of which were orders of magnitude below the current occupational exposure limit of $2.5 \mathrm{mg} / \mathrm{m}^{3}$, although concentrations up to $0.3 \mathrm{mg} / \mathrm{m}^{3}$ had been recorded over short periods. The study sample comprised children aged $6 \cdot 8-7 \cdot 8$ years from 39 schools in the borough. Information about respiratory symptoms and potential risk factors for respiratory disease was elicited from parents by a self administered questionnaire. Data were obtained on 1334 children, a response rate of $81.8 \%$. The prevalences of reported wheeze $(11 \cdot 1 \%)$, breathlessness $(7 \cdot 7 \%)$, and chest discomfort $(8 \cdot 6 \%)$ were similar to those in an earlier survey carried out in Southampton by the same method at the same time of year. Cough (prevalence = $18 \cdot 4 \%)$ and chestiness at night (14.6\%) were significantly less common than in Southampton. When sex, social class, housing tenure, passive smoking, and parental history of asthma were taken into account, the prevalences of symptoms at schools within one mile of the foundry were generally lower than in other parts of Walsall. These findings give no support to the hypothesis that foundry emissions cause respiratory disease in children, although an adverse effect in a few sensitive children cannot be ruled out.
\end{abstract}

The Clean Air Act of 1956 was prompted by peaks of mortality associated with the London smogs of the early 1950s. ${ }^{1}$ Such immediate and serious

Department of Medicine 1

P Symington, S Holgate

MRC Environmental Epidemiology Unit

D Coggon

University of Southampton, Southampton General

Hospital, Southampton SO9 4XY consequences of environmental air pollution are no longer apparent in Britain, but complaints of respiratory symptoms from airborne industrial emissions are not uncommon. These complaints can sometimes be evaluated by reference to the reported effects of higher exposures to the same pollutants in the workplace. Findings in men and women of working age, however, cannot necessarily be extrapolated to potentially more vulnerable sections of the population such as children and the elderly.

We describe an investigation into a suspected high prevalence of respiratory symptoms near a foundry in the midland borough of Walsall. A particular concern was the possible adverse effect of foundry emissions on children attending local schools.

\section{Method}

The foundry began operating in 1963 . Initially the local authority received sporadic complaints about airborne emissions from the factory, but in 1985 these evolved into a concerted campaign by local residents. Among other things it was suggested that respiratory symptoms were unusually common in children at nearby schools. In response to these concerns, air monitoring was undertaken at sites around the foundry during 1987 . (Internal report to Walsall Metropolitan Borough Council prepared by Institute of Occupational Health, Birmingham.) Formaldehyde, ammonia, and isocyanates were selected for measurement as emission markers. The survey suggested that long term average exposures to formaldehyde in the local community were several thousand times less than the current occupational exposure limit of $2.5 \mathrm{mg} / \mathrm{m}^{3}$, although concentrations measured over periods of two hours and less were as high as $0.3 \mathrm{mg} / \mathrm{m}^{3}$. Ammonia and isocyanates were only detected on two occasions, again at concentrations well below what is accepted in industry. In 1987 the company abandoned the process that generated isocyanates, but the complaints from local residents continued.

The location of the foundry is shown in the figure. It is one of 20 foundries in Walsall, most of which are sited in the west of the borough. The figure also shows the position of a hazardous waste disposal plant. Like the foundry, this had been an alleged source of illness among local residents although these suspicions were 


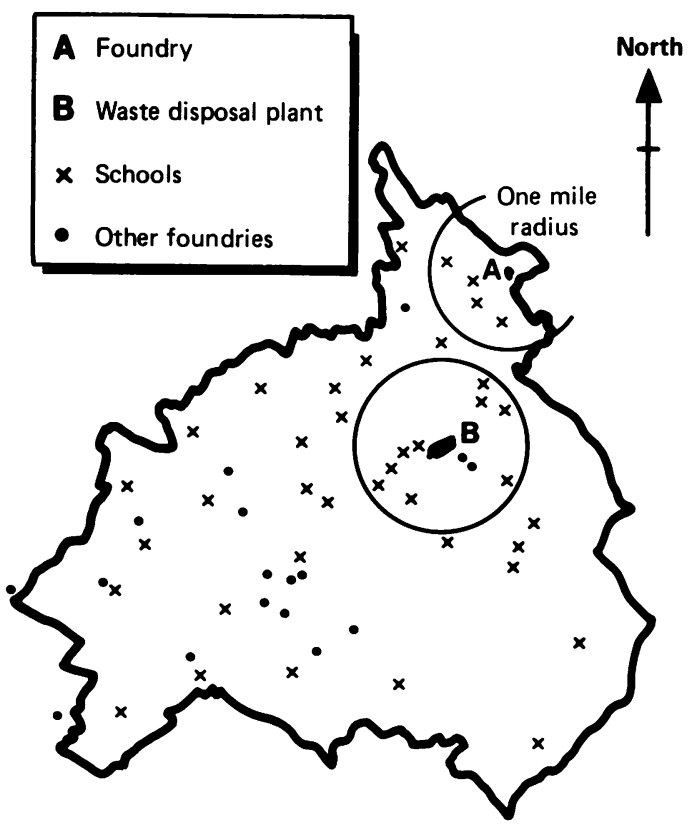

Map of Walsall showing location of foundries, waste disposal plant, and schools

not supported by the demonstration of toxins in the surrounding environment.

Our study sample comprised all children in the top infant year at 39 schools. These were selected with the help of the local education authority. They comprised one school from each ward of the borough, and all schools of the relevant age range within two miles of the foundry or waste disposal plant. Head teachers were approached and all agreed to help.

Information about children's respiratory symptoms and possible risk factors for respiratory disease (social class, housing tenure, passive smoking, and parental history of asthma) was obtained from their parents by self administered questionnaire. The questionnaires were distributed through the schools during June 1989, and non-responders were sent reminders after two weeks.

In our analysis we compared the prevalence of symptoms in Walsall with that recorded in a survey of Southampton school children of the same age who were studied by the same method at the same time of year in $1986 .{ }^{2}$ Also, we calculated symptom prevalences according to whether children attended schools within one mile of the foundry, within one mile of the waste disposal plant, more than two miles from the waste disposal plant and from any foundry, or elsewhere in the borough. The radius of one mile around facilities of interest was chosen to avoid overlap, the foundry and waste disposal plant being about two miles apart. In the comparison between areas of Walsall, prevalences were adjusted for potential confounders by logistic regression.

\section{Results}

Questionnaires were distributed to 1631 children, and $1334(81.8 \%)$ were returned. Response rates from schools within one mile of the foundry $(90 \cdot 1 \%)$ and of the waste disposal plant $(86.0 \%)$ were higher than elsewhere $(80.0 \%)$. The ages of the children studied ranged from $6 \cdot 8-7 \cdot 8$ years.

Table 1 shows the one year period prevalence of symptoms in Southampton and in Walsall. The sex ratios in the two study samples were virtually identical. There were no important differences in the occurrence of wheeze, breathlessness, or chest discomfort, but cough and chestiness at night were reported significantly more often in Southampton, the difference in cough being substantial $(12.3 \%$, $95 \%$ confidence interval $(95 \% \mathrm{CI}) 9 \cdot 0-15 \cdot 6 \%$ ).

Table 2 shows the prevalence of symptoms at schools in different areas of Walsall after adjustment for the potential confounding effects of sex, social class, housing tenure, passive smoking, and parental history of asthma. No consistent pattern emerged from the analysis. Cough was reported most often in children at school near the foundry, but their rates of wheeze, breathlessness, and chest discomfort were lower than in control areas. An analysis based on place of residence rather than place of school produced similar results.

\section{Discussion}

The levels of air pollution that had been recorded at sites around the foundry before this study were low in comparison with those found in many workplaces. This did not, however, exclude the possibility that they might cause respiratory illness in children. Little is known about the effects of industrial air pollution at young ages, but the association of childhood respiratory disease with passive smoking ${ }^{34}$ suggests that children may be unusually susceptible to airborne pollutants.

The questionnaire by which we ascertained symptoms was identical to that used in an earlier survey in Southampton. When it had been reissued to a sample of children at an interval of four months, answers had proved largely reproducible. ${ }^{2}$ The higher response rates in schools near to the foundry and waste disposal plant are unlikely to have been an important source of bias, as the differences (which probably reflected greater local interest in the survey) were small. Similarly, the response rate in Walsall overall was close to that obtained in Southampton $(84 \%)$.

A more serious concern was the possibility of differential reporting of systems. Such bias would not necessarily be eliminated by the adjustment of prevalences for social class and parental history of asthma. In particular, parents in those places where 
Table 1 One year period prevalence (\%) of symptoms in Walsall and Southampton

\begin{tabular}{|c|c|c|c|}
\hline Symptom $\star$ & $\begin{array}{l}\text { Walsall } \\
(n=1334 ; \text { boys }=50.9 \%)\end{array}$ & $\begin{array}{l}\text { Southampton } \\
(n=1274 ; \text { boys }=51 \cdot 1 \%)\end{array}$ & Difference (95\% CI) \\
\hline $\begin{array}{l}\text { Wheeze } \\
\text { Breathlessness } \\
\text { Cough } \\
\text { Chest discomfort } \\
\text { Chestiness at night }\end{array}$ & $\begin{array}{r}11 \cdot 1 \\
7 \cdot 7 \\
18 \cdot 4 \\
8 \cdot 6 \\
14 \cdot 6\end{array}$ & $\begin{array}{r}11.9 \\
6.9 \\
30.7 \\
10.5 \\
19.3\end{array}$ & $\begin{array}{c}-0.8(-3.2 \text { to } 1.6) \\
0.8(-1.2 \text { to } 2.8) \\
-12.3(-15.6 \text { to }-9.0) \\
-1.9(-4.1 \text { to } 0.4) \\
-4.7(-7.6 \text { to }-1.8)\end{array}$ \\
\hline
\end{tabular}

«The questions by which symptoms were elicited were:

(1) Has your child ever had an attack of wheezing (by wheezing I mean noisy breathing with a whistling sound coming from the chest not the throat)?

(2) Has your child ever been either unexpectedly breathless at rest or more breathless than you would expect after exercise (by breathless I mean out of breath or puffed)?

(3) Has your child ever seemed to cough more (or to get more coughs) compared to other children?

(4) During the last 12 months has your child ever appeared to suffer from chest pain or discomfort?

(5) Does your child sometimes have difficulty sleeping because of chestiness?

Parents who answered yes to questions (1) to (3) were asked further whether the symptom had occurred in the past 12 months.

anxieties about pollutants had been aroused might be expected to report symptoms more readily than the average. This would tend to exaggerate prevalences in the neighbourhood of the foundry, but it would not lead to a real effect of pollution being missed.

The reported prevalence of symptoms in Walsall was, if anything, lower than in Southampton. We could not allow for potential confounders other than sex when comparing between towns, but the schools studied in Southampton were representative of the city as a whole, and a substantial confounding effect seems unlikely. The Southampton schools were not situated close to any obvious sources of air pollution. The higher prevalence of cough in Southampton is difficult to interpret, but may reflect parents' perceptions of symptoms in their child's peers. Unlike other questions, the enquiry about cough entailed explicit comparison with other children (table 1). Whatever the explanation, the comparison between towns gave no indication of excess childhood respiratory disease in Walsall.

When comparing areas within Walsall, we classified children according to the location of their school rather than their place of residence. This was because initial complaints had focused on schools. Most children lived close to their school, however, and an analysis based on place of residence produced similar findings.
In the absence of direct measures of pollution throughout the borough, schools were grouped according to their distance from the foundry and from other possible sources of pollution. The prevalent wind in Walsall is from the south west, but we lacked the other information needed to model the distribution of airborne pollutants in any more credible way. No schools were immediately downwind of the foundry, but our radius of one mile around the factory included those schools from which complaints had been received.

Despite the concerns which led to the survey, no excess of symptoms was found in this area. Our failure to show a problem could not be explained by a confounding effect of sex or social class, or by exposure to other sources of pollution in control areas. After allowance for possible confounders, symptoms were most prevalent in the schools that were furthest from industrial facilities.

Previous studies of air pollution and respiratory illness in children have focussed mainly on particulates and sulphur dioxide. Early surveys carried out when pollution was relatively severe indicated associations both with respiratory symptoms $^{56}$ and impaired pulmonary function. ${ }^{7}$ The relation has not been so consistently apparent in more recent investigations, ${ }^{8-15}$ perhaps because effects at lower levels of exposure are small. The sensitivity of

Table 2 Prevalence (\%) of symptoms in areas of Walsall

\begin{tabular}{|c|c|c|c|c|}
\hline Symptom & $\begin{array}{l}\text { Schools within one mile } \\
\text { of the foundry } \\
(n=109)\end{array}$ & $\begin{array}{l}\text { Schools within one mile } \\
\text { of the waste disposal plant } \\
(n=245)\end{array}$ & $\begin{array}{l}\text { Schools more than two miles } \\
\text { from the waste disposal } \\
\text { plant or any foundry } \\
(n=104)\end{array}$ & $\begin{array}{l}\text { Other schools } \\
(n=876)\end{array}$ \\
\hline $\begin{array}{l}\text { Wheeze } \\
\text { Breathlessness } \\
\text { Cough } \\
\text { Chest discomfort } \\
\text { Chestiness at night }\end{array}$ & $\begin{array}{r}9 \cdot 7 \\
5 \cdot 4 \\
28 \cdot 8 \\
6 \cdot 6 \\
14 \cdot 5\end{array}$ & $\begin{array}{l}11 \cdot 1 \\
10 \cdot 1 \\
15 \cdot 4 \\
10 \cdot 8 \\
11 \cdot 8\end{array}$ & $\begin{array}{r}12 \cdot 9 \\
8 \cdot 2 \\
26 \cdot 2 \\
12 \cdot 0 \\
26 \cdot 8\end{array}$ & $\begin{array}{r}11 \cdot 1 \\
7 \cdot 3 \\
17 \cdot 0 \\
7 \cdot 8 \\
13 \cdot 9\end{array}$ \\
\hline
\end{tabular}

Prevalences are adjusted for sex, social class, housing tenure, passive smoking, and parental history of asthma. 
children to foundry gases has not been considered before.

Our survey gives no support to the hypothesis that low concentrations of formaldehyde and other foundry emissions cause respiratory disease in children. It does not, however, exclude the possibility that a few children might be sensitive or that higher exposures than those experienced in Walsall might be harmful. Had we found an increased prevalence of symptoms in Walsall or in the vicinity of the foundry, we would have gone on to measure respiratory function in our study sample; given the results obtained, we do not think that this would be useful.

This study was supported by a grant from Walsall Metropolitan Borough. We thank Dr G M Singal of Walsall District Health Authority and the staff of the Borough's Environmental Health and Consumer Services Department for their helpful advice; and the head teachers of participating schools.

Requests for reprints to: Dr D Coggon, MRC Environmental Epidemiology Unit, University of Southampton, Southampton General Hospital, Southampton SO9 4XY.

1 Royal College of Physicians of London. Air pollution and health. London: Pitman, 1970.

2 Clifford RD, Radford M, Howell JB, Holgate ST. Prevalence of respiratory symptoms among 7 and 11 year old school children and association with asthma. Arch Dis Child 1989;64:1118-25.

3 Colley JRT, Holland WW, Corkhill RT. Influence of passive smoking and parental phlegm on pneumonia and bronchitis in early childhood. Lancet $1974 ;$;i:1031-4.

4 Bland M, Bewley B, Pollard V, Banks MH. Effect of children's and parent's smoking on respiratory symptoms. Arch Dis Child 1978;53:100-5.

5 Douglas JWB, Waller RE. Air pollution and respiratory infection in children. British Journal of Preventive and Social Medicine 1966;20:1-8.

6 Lunn JE, Knowelden J, Handyside AJ. Patterns of respiratory illness in Sheffield infant schoolchildren. British Journal of Preventive and Social Medicine 1967;21:7-16.

7 Holland WW, Halil T, Bennett AE, Elliott A. Factors influencing the onset of chronic respiratory disease. BMJ 1969;2:205-8.

8 Melia RJW, Florey C du V, Swan AV. Respiratory illness in British schoolchildren and atmospheric smoke and sulphur dioxide 1973-7. I. Cross-sectional findings. J Epidemiol Community Health 1981;35:161-7.

9 Melia RJW, Florey C du V, Chinn S. Respiratory illness in British schoolchildren and atmospheric smoke and sulphur dioxide 1973-7. II. Longitudinal findings. J Epidemiol Community Health 1981;35:168-73.

10 Dockery DW, Ware JH, Ferris BG, Speizer FE, Cook NR, Herman SM. Change in pulmonary function in children associated with air pollution episodes. J Air Pollut Control Assoc 1982;32:937-42.

11 Schenker MB, Vedal S, Batterman S, Samet J, Speizer FE. Health effects of air pollution due to coal combustion in the Chestnut Ridge region of Pennsylvania: Cross-section survey of children. Arch Environ Health 1986;41:104-8.

12 Kagamimori S, Katoh T, Naruse Y, et al. The changing prevalence of respiratory symptoms in atopic children in response to air pollution. Clin Allergy 1986;16:299-308.

13 Vedal S, Schenker MB, Munoz A, Samet JM, Batterman S, Speizer FE. Daily air pollution effects on childrens respiratory symptoms and peak expiratory flow. Am J Public Health 1987;77:694-8.

14 Hunt TB, Holman CDJ. Asthma hospitalisation in relation to sulphur dioxide atmospheric contamination in the $\mathrm{K}$ winana industrial area of Western Australia. Community Health Stud 1987;11:197-201.

15 Charpin D, Kleisbauer JP, Fondarai J, Graland B, Viala A Gouezo $F$. Respiratory symptoms and air pollution changes in children: The Gardanne coal-basin study. Arch Environ Health 1988;43:22-7.

Accepted 7 January 1991 